\title{
UMA ABORDAGEM DO CONCEITO DE CAOS E DO CONCEITO DE DETERMINISMO PRESENTES NA FÍSICA E NA TEORIA DE CIRNE-LIMA*
}

SINTESE - A filosofia como sistema, segundo Cirne-Lima, só poderá ser justificada se caos e determinismo puderem ser justificados. Trata-se de uma unificação entre a "substância" de Spinoza e o "eu livre" de Kant. Para que isso possa ser justificado busca-se na Física um paradigma de discussão. Podemos encontrar na Fisica uma teoria que corrobore a idéia de uma justificação via sistema, como pretende CirneLima, isto é, onde haja uma unificação entre caos e determinismo?

PALAVRAS-CHAVE - Caos, determinismo, liberdade, necessidade, contingência.
ABSTRACT - According to Cirne-Lima, the philosophy as a system oniy will be justified if we agree that chaos and determinism can be in it unified. This idea could be understood as the unification of the "I free" of Kant and the "substance" of Spinoza. In order to justify CirneLima's idea is necessary to take physics as a philosophical paradigm. Is possible, as intended Cirne-Lima, to search in the physics a theory that corroborates the idea of philosophical system? Is possible to unify chaos and determinism?

KEY WORDS - Chaos, determinism, freedom, necessity, and contingence.

"Devemos considerar o estado presente do universo como efeito dos seus estados passados e como causa dos que se vão seguir. Suponha uma inteligência que pudesse conhecer todas as forças pelas quais a natureza é animada e o estado em um instante de todos os objetos- uma inteligência suficientemente grande que pudesse submeter a todos esses dadcs à análise - ela englobaria na mesma fórmula os movimentos dos maiores corpos do universo e também dos menores átomos: nada the seria incerto e o futuro, assim como o passado, estaria presente ante seus olhos" (Laplace, 1990. p. 326).

* O presente texto é resultado das anotações e discussōes ocorridas nas aulas do professor CirneLima no Curso de Pós-Graduação em Filosofia da PUCRS. São referentes ao primeiro semestre de 1998. Trata-se de uma abordagem abrangente e que não tem pretensão de esgotar o assunto. Este trabalho compõe o mapa teórico da revista, mesmo não tendo sido apresentado no Congresso de Dialética.

** Mestrando em Filosofia da PUCRS.

\begin{tabular}{|l|l|l|l|l|l|}
\hline VERITAS & Porto Alegre & v. 43 & $n^{2} 4$ & Dezembro 1998 & p. 1129-1139 \\
\hline
\end{tabular}


Até a metade do século XIX, o determinismo era tido como pressuposto teórico tanto nas ciências naturais como nas ciências humanas. Segundo Popper, nesse pressuposto, todos os acontecimentos do mundo são preestabelecidos e o futuro é fixo como o passado. Em oposição, conforme ele, temos a concepção indeterminista, que afirma existirem acontecimentos que não são preestabelecidos e, onde o futuro não é fixo.

A concepção de determinismo já era comum entre os gregos. A idéia de uma previsibilidade absoluta estava presente, por exemplo, no oráculo de Delfos. Em Delfos, o deus do oráculo era Apolo e, falava através de uma sacerdotisa, Pítia, que ficava sentada próxima a uma fenda na terra. Dessa fenda subiam vapores inebriantes que colocavam Pítia numa espécie de transe. $E$ isto era necessário para que ela se tornasse o meio pelo qual Apolo falava. Muitos chefes de estado não ousavam entrar numa guerra ou tomar decisões importantes sem consultar o oráculo, o qual lhes revelava o futuro. Na Antigüidade Clássica, a questão do determinismo aparece quando alguns pensadores se propõe "entender" os fenômenos naturais. Em 585 a. C., Tales de Mileto previu corretamente um eclipse. Um sucesso que certamente influenciou as concepções preditivas já existentes. Entre os présocráticos começou a ser forjada a visão de um comportamento necessário e bem regulado para o universo material. Leucipo sintetizou essa idéia numa frase que se tornou ponto de referência desde então: "Nenhuma coisa se engendra ao acaso, mas todas a partir da razão e por necessidade". Esse determinismo transmitido pelos mitos gregos invadiu a idade média, onde a igreja se tornou uma das maiores divulgadoras.

Muitos sistemas filosóficos foram partidários das concepções deterministas, exemplos disso estão nos sistemas de Platão, Plotino e Procio e, ainda mais tarde, em Espinosa e Hegel. Na modernidade a influência necessitarista é muito forte, por exemplo, nas teorias do determinismo histórico (concepção segundo a qual existem leis históricas que permitem fazer predições sobre o futuro da humanidade), como é o caso do marxismo.

O grande problema porém das teorias deterministas é a exclusão total da contingência e da liberdade. Um mundo sem contingência e sem liberdade sacrifica a historicidade, o livre-arbítrio e consequentemente o próprio individuo.

No decorrer da história, muitos pensadores perceberam esse problema, é o caso de Aristóreles, Alberto Magno, Tomás de Aquino, Boa-Ventura, Duns Scotus e Guilherme de Ockam. Na modernidade temos ainda, um grupo que vai de Hobbes até Hume e Locke. Dentro do Idealismo alemão, Schelling e Hegel foram os primeiros a perceberem a faita de contingência decorrente do necessitarismo, mesmo permanecendo necessitaristas. Enquanto isso Kant, também ciente dos problemas dai decorrentes, sai pela tangente e cria a teoria dos dois mundos para salvar a liberdade.

Voltando a linha necessitarista da filosofia, temos que Hegel, se propõe a algo novo, a saber, conciliar a substância de Espinosa e o eu livre de Kant. Segundo afirma Cirne-Lima, em Dialética para principiantes, Hegel, por um lado percebe o problema do necessitarismo como este foi posto por Espinosa; por outro lado quer salvar a liberdade como esta foi descrita e afirmada por Kant. (cf. p. 211) Mesmo que Hegel possa ser colocado na tradição dos pensadores necessitaristas, há den- 
tro de sua obra um espaço que deseja comportar, ao mesmo tempo, necessidade e contingência. Hoje na contemporaneidade, o professor Cirne-Lima retoma esse intento hegeliano.

Além das chamadas ciências humanas, as ciências naturais também foram influenciadas pelas teorias deterministas. Esse é o caso da Física, onde, propriamente dito, temos a física clássica como maior exemplo de determinismo. Na física clássica, ou física newtoniana, não existe espaço para a contingência, para o acaso e para o caos. No final do século passado e início deste, alguns físicos e matemáticos, como é o caso de Henri Poincaré, descobrem que sistemas altamente irregulares, sem periodicidade alguma, podem comportar-se de acordo com leis deterministas, inclusive leis muito simples. Tais sistemas, hoje chamados caóticos (caos determinístico) são fortemente dependentes das condições iniciais, ou seja, uma mínima alteração no começo produz drásticas alterações futuras. Compreendia-se que, como na prática nunca se consegue controlar (ou saber) com enorme precisão todas as variáveis envolvidas, uma mínima diferença em seus valores iniciais, alteraria grandemente a evolução futura. Esse caos determinístico, que como vimos se fundamenta no déficit de conhecimento, acabou sendo apenas uma manifestação sofisticada e pós newtoniana do determinismo clássico. Com o estudo da física subatômica através da mecânica quântica, ressurge a idéia do caos, não como caos determinístico; mas agora como uma propriedade da própria natureza. ${ }^{1}$

A Física hoje possui várias teorias que buscam explicar o real com cada vez mais precisão. Ressaltamos, dentre essas teorias, além da mecânica quântica, a Teoria da Relatividade. Muitos físicos possuem como intento uma unificação entre as leis que regem o mundo subatômico e as leis que regem o macrocosmos. Se isso for possivel, quais serão as repercussões dentro da idéia da filosofia como sistema? Como se poderá justificar a liberdade? Como ficará a proposta de CirneLima se o mundo for determinístico? Mas se, de um outro modo, se a realidade pudesse ser, supostamente, organizada pela estrutura da física quântica (determinismo + caos), como ficaria a justificação da historicidade? 0 indivíduo seria levado em conta em suas manifestações? Haveria necessidade de uma Ética? E, finalmente, a proposta renovada de Cirne-Lima teria respaldo?

\section{1 - Caos e determinismo na física}

Na virada deste século, desencadearam-se duas grandes revoluções no tranqüilo mundo da física, a saber, a descoberta da teoria da relatividade e da mecânica quântica. Isso acontece duzentos anos após a publicação da principal obra de Newton, Princípios matemáticos da filosofia natural - 1687.

1 Aiguns cientistas acreditam porém que o caos na mecânica quântica surge somente quando a medida está sendo feita e, que em essência, a mecânica quântica também está dentro da tradição determinista. Trabalharemos aqui nesse texto com a hipótese defendida pela maicria dos físicos, isto é, com aqueles que afirmam que uma parte da mecânica quântica não é computávei e, que não existe um algoritmo que possa descrevê-la, essa parte seria responsável pelo indeterminismo e pelo livre-arbitrio. 
O paradigma newtoniano era baseado na idéia de forças que agem localmente e na descrição matemática através de equações diferenciais. A consagração desse paradigma aconteceu quando um físico inglês, chamado Haley, conseguiu prever a passagem de um cometa, usando as leis de Newton. O determinismo, que é característica principal da física newtoniana, advém da compreensão de que é possível, através do uso de algumas leis fixas (leis naturais) entender todos os fenômenos da natureza. Já, que a própria natureza, é compreendida como algo simples e estático. Sua compreensão depende apenas do conhecimento das condições iniciais dos fenômenos implicados.

Nos escólios I e II dos Princípios Matemáticos está um bom exemplo da linearidade necessitarista da teoria de Newton, trata-se de sua concepção de Espaço e Tempo: "O tempo absoluto, verdadeiro e matemático flui sempre, igual por si mesmo e por sua natureza, sem qualquer relação com qualquer coisa externa" "O espaço absoluto, por sua natureza, sem nenhuma relação com algo externo permanece sempre semelhante e imóvel" [...] (p. 156).

Porém Newton, ao tentar compreender tudo via visão determinista, começa a incorrer em algumas dificuldades. Uma delas foi citada por ele mesmo em 1802, quando buscava compreender e prever o movimento da lua, no qual interagem o sol e a terra. "A irregularidade do movimento da lua tem sido a justa lamentação dos astrônomos; sempre olhei para isso, como uma grande desgraça, que um planeta tão perto de nós como está a lua, que poderia ser tão maravilhosamente útil por seu movimento, tão bem como por sua luz e atração [...], tenha sua órbita tão incontavelmente variada que é temerário"3 (p. 12, grifo nosso).

Esse tipo de "irregularidades" dos movimentos, mesmo que preocupasse, não era decisivo nas pesquisas desenvolvidas pelos adeptos do determinismo. Dessa forma, eram esquecidos ou remetidos para uma perspectiva de resolução futura. Compreendia-se que não havia problemas que não pudessem ser integrados, mas apenas ainda não resolvidos. 0 que temos, daí em diante, é uma propagação cada vez maior das teorias desenvolvidas por Newton e seus sucessores. As previsões sobre o movimento das marés, a forma da terra, o movimento dos cometas, a existência de planetas, a dinâmica dos corpos, entre outros, deram alento a isso. Um dos exemplos da propagação do ideário newtoniano está em, Laplace, que se tornou um grande defensor do necessitarismo. Foi ele que escreveu, em 1814 no seu Ensaio filosófico sobre as probabilidades, a respeito de uma inteligência superior, o chamado "demônio de Laplace", que poderia abarcar todo o conhecimento futuro e passado.

Na segunda metade do século XIX, o desenvolvimento da teoria cinética dos gases produz profundas conseqüências na física ao gerar um modelo estatístico que descrevia sistemas com muitos graus de liberdade: o elemento estatístico entrava no desconhecimento das condições iniciais do sistema, constituído de um número muito grande de partes. A constatação desse fenômeno causa um impasse na estática física clássica. Porem, com o intuito de dar uma resposta a essa nova

2 Utilizamos aqui a tradução dos "Principios matemáticos da filosofia natural" que está na coleção Os Pensadores, ed. Nova Cultural, 1987.

3

in revista Ciência Hoje, número 80, vol. 14. 
realidade, surgem, no fim do século XIX, alguns fisicos que forjam uma visão de lei natural que torna as leis científicas contingentes em relação a liberdade criativa do homem. O grande objetivo era o de introduzir o acaso na mecânica clássica através da dependência hipersensivel das condições iniciais. Nascia aí o acaso determinístico.

Essas novas idéias surgem através de vários físicos e matemáticos, dentre eles citamos: Jacques Hadamard, Duhen e Poincaré. A nova realidade "casuística" apontada pela teoria cinética dos gases pode ser caracterizada:

- pela complexidade das causas, ou seja pelo fato de que, ao analisarmos qualquer sistema sempre levamos em conta apenas parte das influências (forças) às quais o objeto está submetido;

- pela sensibilidade dos sistemas às condições iniciais, ou seja pela grande influência dos pequenos erros iniciais, mesmo quando as leis forem inteiramente conhecidas.

Essa última característica foi demonstrada, no fim do século XX, pelo matemático Hadamard. Já o papel de Duhen foi o de fazer uma dedução matemática a partir da demonstração de Hadamard. Mas o grande teórico do acaso determinista foi sem dúvida Henri Poincaré (1854-1912). Foi ele o primeiro a adquirir uma visão mais giobal da nova mecânica. Em sua obra Ciência e método, ele expõe com clareza a problemática resultante da sensibilidade do sistema às condições iniciais. Em uma certa passagem do livro ele expõe resumidamente como é possivel introduzir o acaso na física clássica. Poincaré faz isso lembrando as idéias expostas por Maxel: "Uma causa muito pequena que escapa de nossa observação determina um efeito considerável que não podemos deixar de ver; dizemos então que o efeito é devido a chance. Se soubéssemos exatamente as leis da natureza e a situação do universo no instante inicial poderiamos prever exatamente a situação do mesmo universo em um momento posterior. Mas mesmo se fosse 0 caso de as leis da natureza não serem segredo para nós, poderíamos ainda conhecer as condições iniciais somente 'aproximadamente'".

Podemos perceber, neste pequeno relato, uma das mais fortes características dos caos deterministico, a saber, o argumento do déficit de conhecimento. Segundo esse argumento, não podemos explicar todos os fenômenos, porque nos faltam condições, até mesmo inteligíveis, que nos levem ao acesso às leis gerais. $\mathrm{O}$ que fica implícito porém, nesse argumento, e isso é o mais importante para nós, é que não foi abandonada a teoria do "determinismo total", apenas está descartada, momentaneamente, a nossa capacidade de chegar até ele. É essa "incapacidade" que proporciona 0 acaso.

Segundo Rosendo A. Yunes, na obra A Organização da matéria, "o acaso significa indeterminação, causalidade. Esta indeterminação pode ter sua origem em nossa falta de capacidade de conhecer ou pode ser parte da realidade mesma"(p. 28).

Como já vimos, o que citamos como caos até agora, está relacionado a incapacidade, que nos é inerente de conhecer. Esta visão foi denominada na história da física como caos determinístico e, tinha como objetivo salvar a física clássica das peripécias dos fenômenos indeterminados. Ocorre porém, que esse conceito 
de caos passa a ser abandonado no princípio desse século. Mesmo que as questões anteriormente levantadas permanecessem essenciais, elas passaram a ser vistas sob nova óptica e sob novos condicionamentos. No fim do século passado houve fracasso quando se tentou explicar o mundo subatômico $(\mathrm{m} \rightarrow 0)$ com as leis de Newton. A partir disso, vê-se surgir a mecânica quântica. Trata-se de uma nova fase da física, que agora vai abordar preferencialmente as massas que tendem a zero $(m \rightarrow 0)$.

Junto ao início do século XX também temos o surgimento da Teoria Geral da Relatividade (TGR), criada por Einstein e que trata dos corpos que possuem velocidade que tendem à velocidade da luz $(\mathrm{v} \rightarrow \mathrm{c})$. A física de Einstein revolucionou as teorias físicas até então aceitas. Pois além de poder ser aplicada aos gigantescos corpos do universo, ela também chegou aos mesmos resultados da física de Newton, quando aplicada em massas que deslocam-se a velocidades muito menores do que a da luz, isto é, a velocidades que vemos. Porém, no campo subatômico a TGR não obteve sucesso. O grande intuito de muitos dos físicos hoje é o de unificar a TGR com a mecânica quântica.

Abandonamos aqui a física de Einstein para abordarmos o novo conceito de caos que surge com a mecânica quântica. Segundo David Ruelle, em Acaso e Caos, "a mecânica quântica faz com que o acaso intervenha de maneira nova e intrínseca" (p. 68). De maneira nova porque estamos agora em uma realidade totalmente diferente, estamos no campo dos elétrons, dos nêutrons, dos prótons, dos fótons [...] onde as maiores massas são as das moléculas e os dos átomos. $E$, é de maneira intrínseca, porque agora o acaso é parte integrante da natureza dos fenômenos e, não mais algo estranho e exterior como no caos determinístico. A descrição prọbabilística (caos) na mecânica quântica é encarada como algo essencial para a descrição dos fenômenos físicos.

$\mathrm{O}$ caos quântico não é determinístico; mas sim aleatório. Não é resultado de algum tipo de déficit de conhecimento, mas surge espontaneamente de dentro do sistema. Porém, o caos não é a totalidade dentro da mecânica quântica; se assim fosse cairíamos num sistema absolutamente imprevisivel. Na física quântica o caos existe junto ao determinismo, porém não é determinista. Explicaremos melhor isso através do seguinte exemplo:

$\mathrm{Na}$ eletrosfera do átomo existem vários níveis de energia permitidos para os elétrons, chamaremos esses níveis de "camadas". Quando um elétron recebe energia suficiente, ele é arrancado de sua camada original e salta para uma mais distante (ou mais energética). Porém, nunca se sabe, com certeza, qual dos elétrons, que estão localizados nas outras camadas mais externas, vai ocupar o lugar do elétron que foi arrancado. Há dessa forma uma reorganização probabilística. 


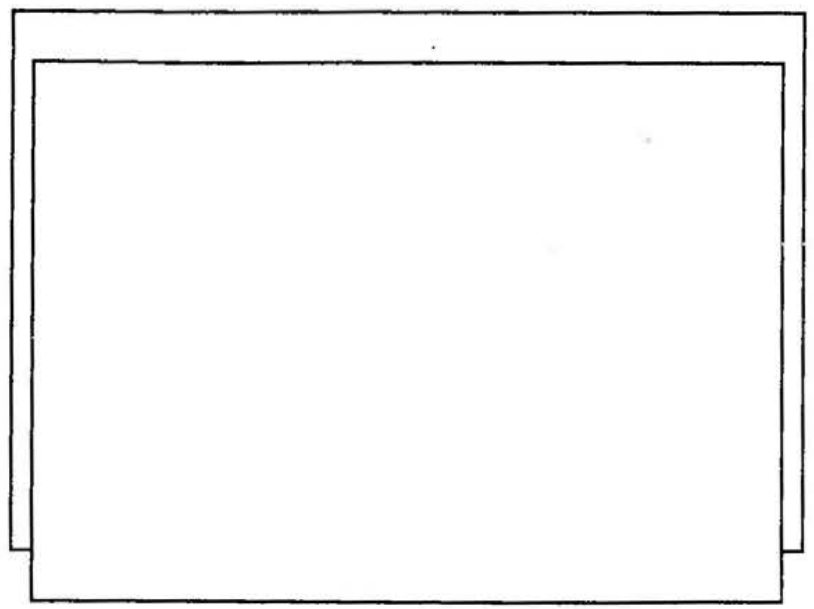

Fig.: Representação do átomo conforme modelo de Bohr

Com isso, podemos perceber, que na física quântica convivem as leis e o acaso, o determinado e o indeterminado. Seguindo o exemplo acima, temos que: a estrutura do átomo, a organização em camadas para os elétrons e, o movimento resultante do recebimento de energia são estruturas determinadas, já o movimento de preenchimento das camadas, especificamente o espaço a ser ocupado pelo elétron que recebeu energia, é uma estrutura caótica, aleatória, indeterminada.

\section{2 - Caos e determinismo na Filosofia}

\section{1 - Uma aproximação entre a fisica quântica e a proposta filosófica de Cime-Lima}

O termo caos, trabalhado até agora como um conceito físico, pode ser substituido, na filosofia, de forma equivalente por contingência. O nosso intuito é o de mostrar, aqui, que há uma proximidade entre a física quântica, no que se refere a relação entre determinismo e caos, com a proposta, retomada de Hegel por CirneLima, ou seja, de conciliar a substância de Espinosa com o Eu livre de Kant.

A história da filosofia pode ser organizada de modo que: de um lado possam ser colocados os dialéticos e, de o outro, os analíticos. Os primeiros defendem como fundamento o jogo dos opostos e, os últimos a análise como única forma legitima de compreender o pensamento. Os filósofos filiados a essas duas concepções podem assim ser esquematizados:

- Dialéticos: Platão, Prócolo, Plotino, Scotus Eriúgena, Nicolaus Cusanus, Fichte, Schelling, Hegel e Marx.

- Analíticos: Aristóteles, Alberto Magno, Tomás de Aquino, Duns Scotus, Ockham, Trendlenburg, Eduard von Hartman, Frege.

Como características, primeiramente podemos salientar que a linha dialética possui, como teoria maior, a busca pela construção de um sistema universal. 0 
objetivo é a organização de um sistema necessitário que explique todos os fenômenos do mundo, integrando-os dentro de uma única substância. Esse necessitarismo ontológico pode também ser chamado de Absoluto. Com relação ao absoluto, isto é, a essa concepção de mundo ordenada em camadas de necessidade, podemos salientar que foi Espinosa o seu mais enfático defensor. Segundo CirneLima em Sobre a Contradição, Espinosa num gesto de gigante arrancou o Absoluto de uma transcendência determinada de forma meramente negativa, e, começa de maneira totalmente conseqüente, com um ser que é necessário e tem de existir necessariamente e que, como primeira-última causa, é causa de si mesmo e também causa de tudo o mais. $O$ mundo e as coisas do mundo são apenas atributos e modificações da substância que é uma só, uma e única, a qual, de forma necessária, deixa sair de dentro de si e de sua necessidade interna a multiplicidade das coisas. [...] Para Espinosa, esse absoluto, que é fonte e origem de todas as coisas, está no âmago de todo o universo (cf. p. 81).

Podemos perceber em Espinosa o cerne do necessitarismo. Em sua teoria, todas as coisas do mundo são resultado de uma semente contida num ovo inicial. Tudo foi colocado ali dentro dobradinho e, com o passar do tempo, o universo vai se desdobrando. Esse desdobrar não acontece conforme a opinião dos indivíduos, mas sim inexoravelmente. Cabe aceitar, ou ser arrastado (fata volentum ducunt, volentum trahunt). Por desejar a unidade, essa corrente da filosofia acaba esquecendo dos processos históricos que são elaborados pelos indivíduos no seu dia a dia. Da mesma forma a liberdade não possui espaço, pois tudo é necessário e determinado. Se, fôssemos falar "fisicamente" da linha dialética poderíamos dizer que nela não há lugar para o caos, para o acaso. No sistema necessitarista, o caos acaba não tendo valor algum.

Já, a linha analítica, não primou pela idéia de um sistema que abarcasse todas as realidades, mas tratou de levar em conta a história e salvou a liberdade; porém fez isso criando dois mundos. Kant, o maior exemplo disso, cria um mundo da causalidade, da sensibilidade, do determinado, da heteronomia e, também cria um mundo da liberdade, da autocausação, da autonomia. É partindo desse pressuposto que Kant distingue o mundo sensivel do mundo inteligível. O ser humano, enquanto ser racional, faz parte do mundo inteligivel e o que lhe garante isso é a faculdade da razão. A razão distingue-o de todas as outras coisas. É através da razão que o homem consegue eleger regras que submetem as manifestaçöes sensiveis à sua consciência. Os objetos são sempre passivos de obediência, enquanto o homem, que é racional, é ativo, isto é, pode também formular normas. Os seres racionais agem sobre os objetos, enquanto os objetos sofrem a sua ação.

O ser racional, mesmo fazendo parte do mundo inteligível, é um ser que está sujeito ás leis dos dois mundos. Enquanto pertence ao mundo sensível, como parte da natureza, está sujeita às leis naturais; e enquanto pertence ao mundo inteligivel está sob leis que, independente da natureza não são empíricas, mas fundadas somente na razão. No mundo sensivel tudo age subordinado à causalidade natural, mas no mundo inteligível não. Kant, através da criação do mundo inteligível possibilita a liberdade, isso ele mesmo aponta na Fundamentação da Metafísica dos Costumes: "Como o ser racional e, portanto pertencendo ao mundo inteligivel, o homem não pode pensar nunca a causalidade de sua própria vontade, senão sob a idéia da liberdade" [...] (p. 102). 
Como percebemos, a linha analítica, ao contrário da linha dialética, não está preocupada em propor uma síntese, mas preocupa-se em salvar a liberdade do individuo e a sua possibilidade de influenciar na história. Porém, critica-se a forma de como realiza isso, isto é, criando dois mundos (como fez Kant).

Ainda sobre a tradição necessitarista, queríamos agora ressaltar a importância do trabalho desenvolvido por Hegel. Esse filósofo moderno, pertencente ao chamado grupo do Idealismo Alemão, destacou-se pela defesa da idéia de um Espírito Absoluto. O Absoluto, para Hegel, é a própria razão e, segundo ele cabe aos indivíduos abraçá-la. Do mesmo modo, o absoluto é o próprio Estado, onde resta aos seres humanos seguir obedientemente suas leis. Segundo Cirne-Lima, "Hegel inclina-se - sobre isso não há a menor dúvida - para o necessitarismo, no qual uma Razão do Universo, que é totalmente impessoal - e não nós mesmos --, determina o sentido da natureza e da História". (p. 99) ${ }^{4}$

O grande mérito porém de Hegel, e aqui também pode-se acrescentar Schelling, foi de ter notado a necessidade de reintroduzir a contingência para dentro do sistema. O grande intuito é o de reincorporar a liberdade. Porém, no entender de Cirne-Lima, Hegel não consegue contemplar a contingência, mas cai em ambigüidades ${ }^{5}$ (cf. p. 92).

Essa tentativa de colocar a contingência (liberdade) dentro do sistema (substância) feita por Hegel é retomada na contemporaneidade pelo professor Carlos Cirne Lima. Faremos agora aigumas citações do seu livro Sobre a contradição onde encontramos, especificadamente a sua proposta:

\begin{abstract}
"A questão decisiva é a de saber se a necessidade possui e pressupōe, sempre e em todos os casos, como que uma outra face às questões de si mesma, a saber a contingência". (p. 95)

"Toda a questão está em saber se o Absoluto em sua totalidade, ou seja, no todo de seu movimento processual que é tantc lógico como ontológico (...) pode ser pensado sem uma explosiva contradição como sendo ao mesmo tempo absolutamente necessário e como absolutamente contingente".(p. 96)
\end{abstract}

Como podemos perceber, Cirne-Lima busca reconstruir agora de forma diferente de Hegel a passagem da contingência absoluta para a necessidade absoluta. Para isso, segundo ele, é preciso enfraquecer o conceito de necessitarismo dandolhe espaço dentro do sistema; o que não se pode, porém, é enfraquecer o conceito de liberdade. Já, ao enfraquecer o conceito do paradigma necessitário, Cirne Lima não quer estabelecer um dominio da contingência, do caos; mas busca, de outra forma, uma harmonia entre os dois. Se Hegel trabalhava com o conceito de necessidade absoluta como sendo um "Mussen" - "ser necessário", Cirne Lima substitui-o por Sollen - "dever ser". Da mesma forma, Cirne Lima propõe um "desendurecimento" do que Hegel entendia pelo movimento triádico Tese, Síntese e Antítese, o que se propõe, agora, é um espaço para não só uma antítese, mas para várias (A1, A2, A3...) e, se são possíveis várias antíteses, são possiveis também várias sínteses (S1, S2 S3...). 
Com a abertura de um espaço para a contingência dentro do absoluto, Cirne Lima possibilita que a liberdade faça parte do sistema e, com a liberdade, a história passa a ter a participação dos indivíduos. Com o livre-arbítrio, o homem se torna um ser de responsabilidades e que por isso, tem necessidade de uma Ética.

A gênese e o desenvolvimento do mundo não podem ser explicados por uma teoria necessitarista. O acaso, o caos possuem tamanha importância, que estão implicitamente ligados e inseridos em algumas das ciências naturais. É o caso por exemplo da Biologia. Se como vimos anteriormente o mundo fosse somente explicado pelas teorias de Newton, não seria possivel justificar a contingência. Hoje, a maiona dos físicos perseguem uma unificação da Teoria Geral da Relatividade com a mecânica quântica. Se, isso for possivel estará provado que o caos e o acaso são pressupostos de nenhuma importância, pois os fenômenos da realidade serão totalmente deterministas, da mesma forma poderemos dizer que a idéia de Sistema, aos moldes da nova proposta de Cirne-Lima ficará prejudicada.

Se, porém, a física não se tornar determinista, a exemplo da mecânica quânti$\mathrm{ca}$, entäo a idéia de Sistema terá respaldo completo. Para isso, a física como ciência terá que possuir os mesmos pressupostos da mecânica quântica, a saber, não abdicar de algumas leis duras e, bem como, de uma maleabilidade proposta pelo caos. Se, a organização da mecânica quântica pudesse servir, supostamente, para todo o universo, teriamos aqui uma possibilidade de comparação direta entre a proposta de Cirne-Lima e a Fisica.

A teoria da evolução dos seres vivos permite a manifestação do caos no seu desenvolvimento. Desta forma, a Biologia acaba cooperando para a construção de uma Ética e de uma Politica. Sem a possibilidade da contingência, não seria possível a justificação da liberdade, o livre arbitrio e a responsabilidade. Assim, como Cirne-Lima usou em seu livro Dialética para principiantes o exemplo da Biologia, como a ciência que está fazendo o uso do caos dentro de sua explicação da gênese do desenvolvimento humano, da mesma forma a Física não poderia ser usada. A Física, como ciência, possui basicamente, três teorias para a explicação da realidade: primeiro a física de Newton (teoricamente já superada, mas ainda muito usada), após a mecânica quântica (mundo subatômico) e a física de Einstein (velocidade próxima da luz). Caso, for possivel, o uso, com sucesso, das leis da teoria da relatividade para resolver todos os processos da física quântica isso ocasionaria a determinação total das leis do universo, voltariamos, então, a um sistema determinista, aos moldes da física de Newton, onde o caos desapareceria ou seria deterministico, por déficit de conhecimento.

De outra maneira, lançamos, em nosso texto, a suposição da possibilidade do uso da estrutura da mecânica quântica no campo hoje dominado pela física de Einstein. Caso, isso for possivel, o caos também será possível. Então a Física junto a Biologia, legitimarão a proposta de um sistema determinístico-contingente na Filosofia e, seria também possivel a justificação da liberdade via idéia de sistema.

Isso tudo confirmaria a idéia de um sistema absoluto, mas um sistema que não está pronto, ao contrário que está sedo feito a cada dia, a cada ação nossa. A totalidade nunca estaria completa e acabada. Dessa forma o "processo total" está ern aberto no qual nós, através de nossas opiniões, manifestaçōes, vontades, influimos e, o que é mais importante, produzimos a história, que não é a priori, mas sempre a posteriori. Seremos, de outro modo, co-determinantes. 
Como mesmo Cirne-Lima afirma e confirma em Filosofia e Sistema: "todos nós somos co-autores do sentido do Universo. Insignificantes, sim, mas verdadeiros co-autores" (p. 26).

\section{Referências bảbliográficas}

BANBEOQUANTZ, A. Molecules, dynamics and life. An introduction to self-organization of mater. Usa: J Witey, 1986.

BERNSTER, i. As idéias de Einstein. SP: Cultrix, 1989.

CHARDNV. T. E fenömeno humano. Madrid: Taurus, 1963.

CHERNBKOV, A. A., ZAGDEEV, R. Z.ZASLAVSKY, G.M Chaos how regulat can it the be? Fhisjes Today, NY, v. 41, p. 27-35.

CHINR, R Deus das formigas, Deus das estrełas. Portugal: Pub. Buropa-América, 1990.

CIRNE-LIMA, C. Dialética para principiantes. EDIPUCRS, Porto Alegre, 1996.

Filosofia e Sistema.

. Sobre a Contradiçāo. EDIPUCRS, Porto Aleore, 1993.

DAVES, P. Dios y la nueva fisica. Barcelona: Salvat, 1986.

EDDFR, J., REMBOUL, H. Biosemiotics a padjgn of biology. Naturwissenchaften, Berin, v. 79, p. 60$67,1992$.

EIGEN, WINKLER, R. $O$ jogo. As leis naturais que regulan o acaso. Listos: Gradiva, 1989.

EFNSTEIV, A. Comment on meyersoris la deduction relativiste. Revue Fhitesexphie de la France eq de I'stranger, v. 105, p. 161-66,1928.

FRIIRE-MAIA, N. Chiaçāo e evofução: Deus, o acaso e a necessidade. Rio die Jahteiro: Ed. Vozes, 1986:

GALILEI, Gatileo. NBWTON, I O ensaiador. Princíphos matemáticos.SP: Nowa Culthaval, 198 ?

GLEICK, J. Caos, a construçầ de uma nova ciència, Gradiva, Fisiboa, 1939.

GUTZWILEER, M.C, "Quantum Caos" Scientific American, p. 26, janeíro de 1992.

HAWKHNG, S.W. Una breve histónia do tempo. Rio de Janeiro: Rocco, 1988.

JASEFOW, R. O tear encantada Lisboe: Ediçẽes 70, 1987.

KAUIFMAN, S. A. Antichaos and adaptation. Sci. Amer. NY, v. 264, p. 64-70, 1991.

KONINCK, C. The hollow universe. Inglatena: Oxford Univ. Press, 1960.

MANDEELBROT, B. Objetos fractais. Lisboa: Gradiva,1991.

OLIVEIRA, Manfredo A. Tópicos sobre dialética. EDIPUCRS, Porto Alegre 1997.

RUDELE, David. Acaso e Caos. tradução de Robuerto Leal Ferreira. SP. Editora da Universidade Estadual Parkista, 1983.

SIEVEIRA, Femando Lang. Determinismo, Previsibilidade e Cáos. in Cademos Cat. Ensino de Fisica v. 10, $n^{2} 2$ p. 137-147, agosto de 1993.

STEWART. 1. Será que Deus joga dados?-A nova matemática do caos.

TARRAGO, MEP. "Unsa conversa sobre o caos", palestra proferida pelo instituto de Fisica jumho/98 PUCRS.

TREFE, J. S. De los atornos a los guarks. Barcelona: Salvat, 1988.

YUNES, Rosendo A. A Organização da Matéria: acaso or informação - Florianópolis: Ed. da UTSC, 1995. Zahar edittor, RJ, 1991. 